BMJ Paediatrics Open

\section{Impact of chronic health conditions and injury on school performance and health outcomes in New South Wales, Australia: a retrospective record linkage study protocol}

To cite: Mitchell $R$, Cameron CM, Lystad RP, et al. Impact of chronic health conditions and injury on school performance and health outcomes in New South Wales, Australia: a retrospective record linkage study protocol. BMJ Paediatrics Open 2019;3:e000530. doi:10.1136/ bmjpo-2019-000530

Received 28 May 2019 Revised 24 July 2019 Accepted 21 August 2019
Check for updates

(c) Author(s) (or their employer(s)) 2019. Re-use permitted under CC BY-NC. No commercial re-use. See rights and permissions. Published by BMJ

For numbered affiliations see end of article.

Correspondence to Dr Rebecca Mitchell; r.mitchell@ mq.edu.au

\section{ABSTRACT}

Introduction Children who have sustained a serious injury or who have a chronic health condition, such as diabetes or epilepsy, may have their school performance adversely impacted by the condition, treatment of the condition and/or time away from school. Examining the potential adverse impact requires the identification of children most likely to be affected and the use of objective measures of education performance. This may highlight educational disparities that could be addressed with learning support. This study aims to examine education performance, school completion and health outcomes of children in New South Wales (NSW), Australia, who were hospitalised with an injury or a chronic health condition compared with children who have not been hospitalised for these conditions.

Method and analysis This research will be a retrospective population-level case-comparison study of hospitalised injured or chronically ill children (ie, diabetes, epilepsy, asthma or mental health conditions) aged $\leq 18$ years in NSW, Australia, using linked health and education administrative data collections. It will examine the education performance, school completion and health outcomes of children who have been hospitalised in NSW with an injury or a chronic health condition compared with children randomly drawn from the NSW population (matched on gender, age and residential postcode) who have not been hospitalised for these conditions.

Ethics and dissemination The study received ethics approval from the NSW Population Health Services Research Ethics Committee (2018HRE0904). Findings from the research will be published in peer-reviewed journals and presented at scientific conferences.

\section{INTRODUCTION}

Participation in school-based education is important for a child's mental, social and physical development. The WHO acknowledges the importance of quality primary and secondary education for all children in their global strategy for children's and adolescents' health. ${ }^{1}$ Any restrictions on the ability of a

\section{What is already known on this topic?}

Poor health can have a negative impact on a child's ability to learn.

- Determining the impact of poor health on learning requires objective measures of education performance.

- There is limited information available regarding a child's ongoing healthcare use while they attend school.

\section{What this study hopes to add?}

A population-level study to examine the impact of injury or chronic disease on children's scholastic performance.

- This study will identify the types of injuries and chronic illness associated with problems with learning at school.

- The developmental timing and need for educational support will be highlighted for chronically ill children accounting for age, gender and illness type.

child to perform to the best of their ability at school may adversely affect their career prospects and long-term quality of life. Traumatic injury or the presence of a chronic health condition, such as diabetes, epilepsy, asthma or mental health conditions, can have an adverse impact on the child's performance at school. ${ }^{2-9}$ Interruptions to education can have a cumulative effect, resulting in being less likely to complete school or attend university and potentially limiting future employment opportunities. ${ }^{10}$ Therefore, early identification and recognition of a child's need for learning support at school is critical.

Worldwide traumatic injury is a common cause of hospitalisation among children. ${ }^{11}$ In Australia, injury is the leading cause of 
hospitalisation among children, with almost 70000 children aged $\leq 16$ years hospitalised each year. ${ }^{12}$ Different types of injuries (eg, burns, traumatic brain injury and orthopaedic injury) and the mechanism of injury (eg, vehicle crash, pedal cycle collision, falls and selfharm) can affect children in different ways. The more serious the injury, often the more adverse impact on the child's psychological and physical health and on the child's family. ${ }^{13}$ Chronic health conditions are prevalent worldwide $^{14}$ and can also have an adverse impact on a child and their ability to perform well at school and to complete their schooling. ${ }^{810}$ Previous research has not always considered objective measures of school performance, instead relying on subjective reports from parents or teachers. ${ }^{815}$ This research has lacked information regarding a child's ongoing healthcare use, ${ }^{8}$ lacked an indication of the severity of the child's injury or illness, ${ }^{10}$ often involved small sample sizes ${ }^{16}$ and has not been able to examine the impact on school performance over a range of ages or over time for the same child. ${ }^{16}$ This study aims to examine education performance, school completion and health outcomes of children who have been hospitalised with an injury or a chronic health condition compared with children who have not been hospitalised for these conditions.

\section{Study objective and aims}

The overall objective is to examine education performance, school completion and health outcomes of children who have been hospitalised with an injury or a chronic health condition (ie, diabetes, epilepsy, asthma or a mental health condition). The specific aims are to:

1. Compare school performance among injured or chronically ill children and a matched comparison group.

2. Examine factors influencing school performance of injured or chronically ill children compared with a matched comparison group, such as sociodemographic (eg, age, gender and socioeconomic), parental (eg, education) and clinical factors.

3. Determine factors that either positively or negatively mediate young people completing high school (years $10,11$ or 12$)$.

4. Assess characteristics of long-term health service utilisation and hospital treatment cost among injury or chronically ill children compared with a matched comparison group.

\section{METHOD AND ANALYSIS \\ Study design}

This will be a retrospective population-level case-comparison study of injured or chronically ill children (ie, diabetes, epilepsy, asthma or mental health conditions). These four health conditions and injury were selected as injuries are the leading cause of hospitalisation in Australia for children aged $1-18$ years, ${ }^{17}$ and the four chronic health conditions represent the most common health conditions experienced by children in Australia ${ }^{18}$ that have previously been associated with having a detrimental impact on learning. ${ }^{2-9}$ This will be a retrospective epidemiological study of children aged $\leq 18$ years at the date of admission for their index hospitalisation in New South Wales (NSW), Australia. It will include matched population-level comparison groups for each health condition.

\section{Data sources}

Nine administrative data collections in NSW will be linked and analysed for this study: hospital admissions, emergency department (ED) presentations, ambulatory mental health client contacts, the Registry of Births, Deaths and Marriages (RBDM) and the Cause of Death Unit Record File (COD-URF) mortality data collections, the National Assessment Plan for Literacy and Numeracy (NAPLAN), school enrolments, high school completions (year 10, 11 or 12) and RBDM birth data.

\section{Information on hospital service use}

Information on hospital service use will be obtained from ED presentation and hospital admission data collections. Hospitalisation data include information on admissions to public and private hospitals and records of patient demographics, source of referral, diagnoses, separation type, acute/non-acute care, Australian Refined Diagnosis Related Groups and clinical procedures. Data collected on ED presentations in public hospitals also include arrival and departure times, triage category, type of visit, provisional diagnosis and clinical procedures.

\section{Ambulatory mental health client contacts}

Ambulatory mental health client contacts includes information regarding the care individuals received from ambulatory specialist mental health services at public hospitals. This includes mental health day programmes, psychiatric outpatients and outreach services, including home visits. It contains information on care provided by hospital-based consultation liaison services to admitted patients in non-psychiatric and hospital emergency settings, care provided by community workers to admitted patients and clients in staffed community residential settings and mental health promotion and prevention services.

\section{Scholastic performance}

The NAPLAN assessments are conducted on all Australian children in primary school years 3 (7-9 years of age) and 5 (9-11 years of age), and secondary school years 7 (11-13 years of age) and 9 (13-15 years of age) and include assessments in five domains: reading, spelling, writing, grammar, punctuation and numeracy. Each domain is scored out of 1000 and translated into bands that indicate whether the child performed above or below the national minimum standard (NMS). Inability to achieve the NMS indicates that a child will have difficulty making progress in school without assistance. ${ }^{19} \mathrm{~A}$ 
child's attendance or absence from NAPLAN assessments will also be obtained.

\section{Parent demographics}

Parents' occupation and highest level of education will be obtained.

\section{School enrolments and school completion}

Information on school enrolment and school changes will be obtained; high school retention to years 10, 11 and 12 will be obtained through records of high school completion awards known as the record of school achievement and the higher school certificate.

\section{Survival}

Mortality data from the RBDM mortality data will provide information on fact of death, and information from the COD-URF will provide information on the cause of death.

\section{Births}

RBDM birth data will provide an NSW population-level sample to identify the comparison cohorts for the injured or chronically ill children.

\section{Case inclusion criteria}

A principal diagnosis of injury (International Classification of Diseases, 10th Revision, Australian Modification (ICD-10-AM): S00-T79) in hospitalisation data during an 18-year timeframe (ie, 1 January 2001 to 31 December 2018 ) and aged $\leq 18$ years at the date of admission. A principal or any diagnosis (up to 50 diagnoses) of diabetes (ICD-10-AM: E09-E14), epilepsy (ICD-10-AM: G40, G41), asthma (ICD-10-AM: J45) or a mental health condition (ICD-10-AM: F10-F99). Different types of mental health conditions have not been individually selected as children with one mental health condition can experience multiple conditions, for example, mood effective disorders (ICD-10-AM: F30-F39) and neurotic disorders (ICD-10-AM: F40-F49), which would result in duplicate case identification. ${ }^{20}$ Mental health condition data will be analysed on receipt of this information and condition groups detailed. Some children may have multiple health conditions recorded, and these cases will be reviewed on receipt of the hospitalisation data and will likely be treated as a 'multiple health condition' group.

\section{Population comparison group criteria}

The population comparison group will consist of children aged $\leq 18$ years who were born in NSW, who had not previously had a hospital admission with a principal diagnosis of injury or a principal or any diagnosis of diabetes, epilepsy, asthma or a mental health condition and who were alive at the date of admission of their matched case. The comparison group will be randomly matched in a 1:4 ratio on age, gender and residential postcode to their matched case.

\section{Sample size calculation}

There will be an estimated 22300 injury $^{12}$ and 16647 chronic disease ${ }^{21-23}$ hospitalisations of children aged $\leq 18$ years each year. To detect a relative risk of 1.5 , with $5 \%$ significance and $80 \%$ power, a minimum sample size of 200 cases will be required with 800 in each comparison group. It is possible that there will be a number of children absent from school for NAPLAN assessments, but this large cohort the study will retain sufficient power for analysis.

\section{Record linkage}

The data linkage component of the study will be conducted by a third party agency, the Centre for Health Record Linkage (CHeReL). To link the data extracts, the $\mathrm{CHeReL}$ retains only the identifying information (eg, first name, last name and date of birth) from each data extract. Linkage is conducted using probabilistic record linkage, which is based on computing the probability that two records belong to the same person. The linkage process creates a project specific linkage key. The project specific key is returned to the CHeReL Data Integration Unit (or the data custodian) along with their original source record identifier. The CHeReL Data Integration Unit (or the data custodian) extracts the approved content variables (excluding identifying information such as names), attaches the project specific linkage key and securely transfers the data extract to the study investigators. The study investigators will then relink the data extracts using the project-specific linkage key and datebased and other content variables.

\section{Classification frameworks}

\section{Geographical identification}

The will be used to identify children living in rural and urban NSW. Residents are assigned to one of five geographical categories using index scores of distance to service centres. ${ }^{24}$ For ease of analysis and reporting, the five categories will be collapsed into: urban (ie, major cities) and rural (ie, inner and outer regional, remote and very remote) ${ }^{25}$

\section{Socioeconomic status identification}

A measure of socioeconomic status will be assigned to each case or comparison using their postcode of residence and the Index of Relative Socioeconomic Disadvantage. ${ }^{26}$ Socioeconomic disadvantage will be partitioned into quintiles from most (ie, 1) to least disadvantaged (ie, 5).

\section{Injury or condition severity}

For injured children, injury severity will be estimated using the International Classification of Injury Severity Score. ${ }^{27}$ The injury severity score is derived for each injured child by multiplying the probability of survival for each injury diagnosis using survival risk ratios (SRRs). Injury severity will be estimated using previously developed SRRs ${ }^{28}$ and will be categorised as minor $(\geq 0.99)$, moderate $(>0.941-<0.99)$ or serious $(\leq 0.941) .{ }^{29}$ Proxy 
Table 1 School performance, school completion and health service use outcome measures

\begin{tabular}{|c|c|c|}
\hline Outcome & Data source & Outcome measure \\
\hline \multicolumn{3}{|l|}{ School performance and completion } \\
\hline NAPLAN - reading & NAPLAN & Number of children above/below NMS \\
\hline NAPLAN - spelling & NAPLAN & Number of children above/below NMS \\
\hline NAPLAN - writing & NAPLAN & Number of children above/below NMS \\
\hline NAPLAN - grammar and punctuation & NAPLAN & Number of children above/below NMS \\
\hline NAPLAN - numeracy & NAPLAN & Number of children above/below NMS \\
\hline School completion - year 10 & $\begin{array}{l}\text { Record of School Achievement and } \\
\text { the Higher School Certificate }\end{array}$ & $\begin{array}{l}\text { Number of children not completing/ } \\
\text { completing year } 10\end{array}$ \\
\hline School completion - year 11 & $\begin{array}{l}\text { Record of School Achievement and } \\
\text { the Higher School Certificate }\end{array}$ & $\begin{array}{l}\text { Number of children not completing/ } \\
\text { completing year } 11\end{array}$ \\
\hline School completion - year 12 & $\begin{array}{l}\text { Record of School Achievement and } \\
\text { the Higher School Certificate }\end{array}$ & $\begin{array}{l}\text { Number of children not completing/ } \\
\text { completing year } 12\end{array}$ \\
\hline \multicolumn{3}{|l|}{ Health service use } \\
\hline ED presentations & ED presentation data & Number of ED presentations \\
\hline Hospital admissions & Hospital admissions data & Number of hospitalisations \\
\hline Hospital length of stay & Hospital admissions data & Total hospital length of stay \\
\hline Hospital treatment cost & Hospital admissions data & Total hospital treatment cost \\
\hline Mental health client contacts & $\begin{array}{l}\text { Ambulatory mental health client } \\
\text { data }\end{array}$ & Number of mental health client contacts \\
\hline
\end{tabular}

ED, emergency department; NAPLAN, National Assessment Plan for Literacy and Numeracy; NMS, national minimum standard.

indicators of severity of the chronic health conditions will be considered, including number of ED presentations or hospital admissions and hospital length of stay. ${ }^{30}$

\section{Outcomes}

The primary outcome measures will be school performance on each of the five NAPLAN domains (ie, reading, spelling, writing, grammar and punctuation and numeracy) above or below the NMS and school completion at years 10,11 or 12. Secondary outcomes will include hospital length of stay, hospital treatment costs, number of hospital admissions, number of ED presentations and number of mental health client contacts, where relevant (table 1).

\section{Data analysis plan}

Data analyses will be conducted using SAS V.9.4. All hospital episodes of care related to the one event (eg, all episodes of care related to the same injury event) will be linked to form a period of healthcare. Child injury and each chronic illness will be examined separately. Depending on sample size, some types of injuries may be examined separately, such as traumatic brain injury. For descriptive analyses, results with cell sizes $<5$ will not be reported to prevent potential identification of individuals. To compare school performance for injured or chronically ill children to their comparison groups, generalised linear regression will assess the difference in proportions of performances below the NMS for each of five NAPLAN domains for the school grades 3, 5, 7 and 9. To identify factors influencing school performance of injured or chronically ill children, factors related to performance below NMS such as sociodemographic (eg, age, gender and socioeconomic), parental (eg, education) and clinical (eg, number of ED presentations, hospital admissions and hospital length of stay) factors (table 2) will be examined using multivariate logistic

Table 2 Potential mediating and explanatory data variables

Type Data variable

$\begin{array}{ll}\begin{array}{l}\text { School performance and } \\ \text { completion }\end{array} & \\ \text { Child } & \text { Age } \\ & \text { Sex } \\ & \text { Socioeconomic status } \\ & \text { Geographic location } \\ \text { Children with an injury } & \text { Injury severity } \\ \text { Children with a chronic } & \begin{array}{l}\text { Proxy indicators of severity will } \\ \text { bealth condition }\end{array} \\ & \begin{array}{l}\text { of ED presentations or hospital } \\ \text { admissions, or total hospital } \\ \text { length of stay. }\end{array} \\ \text { Parent } & \text { Highest level of education } \\ & \text { Occupation } \\ \text { Clinical } & \text { Number of ED presentations } \\ & \text { Number of hospitalisations } \\ & \text { Total hospital length of stay }\end{array}$

ED, emergency department. 
regression. Relative risks, ORs and 95\% CIs will be calculated. It is likely that sensitivity analyses for potential missing values will need to be conducted for some data variables. Potential missing values will be imputed using the discriminant function method with $100 \mathrm{impu-}$ tations using PROC MI. Parameter estimates will be log-transformed and pooled results and $95 \%$ CIs will be generated using PROC MIANALYSE. Analyses will be performed with and without imputed data. In addition, group-based trajectory modelling ${ }^{31}$ will be undertaken to identify clusters of children with similar school performance outcomes over time. Information such as sociodemographic (ie, age, gender and socioeconomic status), clinical and parental education will be used to estimate a child's probability of group membership over time.

To identify factors influencing high school completion at either year 10, 11 or 12 for injured or chronically ill children compared with the comparison group, factors related to poor school completions, including sociodemographic (eg, age, gender and socioeconomic), parental (eg, education) and clinical (eg, ED presentations and hospital admissions) factors will be examined using multivariate logistic regression. Relative risks, ORs and $95 \%$ CIs will be calculated.

The characteristics of long-term health service utilisation and hospital treatment cost among injured or chronically ill children compared with their comparison group will be assessed using a generalised linear model with a log link and gamma error distribution to assess hospital length of stay, hospital treatment costs and the number of hospital admissions during the study period. These will be adjusted for sociodemographic and other characteristics, such as injury severity, as relevant.

\section{Dissemination plan}

Dissemination of research results will be conducted through peer-reviewed journal articles and presentations at relevant professional conferences. Research findings will also be provided to government agencies, including health and education authorities.

\section{Patient and public involvement}

There was no patient involvement in the design of the record linkage study.

\section{Limitations}

There will be some study limitations to take into consideration in the interpretation of findings. Only health conditions that are relevant to a hospital admission are indicated in hospital diagnosis records, so it is possible that some conditions could be underenumerated. The study would identify cases where the child had been hospitalised for the injury or chronic health condition, so would not identify children presenting solely to other medical professionals, such as general practitioners, for treatment. However, children who are hospitalised for their injury or health condition are likely to be the most seriously affected. There will not be an opportunity to examining the validity of diagnoses (except between administrative health records), and it is possible that there could be some misclassification. The NSW ED presentation data does not contain information on ED presentations to private hospitals, so private hospital ED presentations will not be examined. However, almost all (93\%) of ED services are provided by public hospitals in Australia. ${ }^{32}$ In identifying the matched comparison cohorts, the recency of postcode of usual residence may vary between data collections. For example, postcode of residence at birth could vary from postcode of residence while at school.

\section{DISCUSSION}

This research will examine the impact on school performance and high school completion of children who are hospitalised for an injury or a chronic health condition-namely diabetes, epilepsy, asthma or mental health conditions-compared with children who have not been seriously affected and hospitalised for these health conditions. It will identify the characteristics of children who are most likely to be adversely affected by their health conditions. This may include children who have multiple hospital admissions, extended time in hospital, more serious injuries, multiple health conditions, specific types of injuries or children whose primary language is not English or who reside in disadvantaged socioeconomic areas. The study is also likely to include children whose injuries and illnesses are the direct cause of cognitive difficulties resulting in poor educational performance. It is anticipated that research findings will identify any educational outcome disparities with a comparison population and the characteristics of injured and chronically ill children most likely to have problems with learning at school and will highlight where educational support services are most needed.

\section{Author affiliations}

${ }^{1}$ Australian Institute of Health Innovation, Macquarie University, Sydney, New South Wales, Australia

2Jamieson Trauma Institute, Royal Brisbane and Women's Hospital, Brisbane, Queensland, Australia

${ }^{3}$ School of Public Health and Social Work, Queensland University of Technology, Brisbane, Queensland, Australia

${ }^{4}$ Faculty of Medicine and Health Sciences, Macquarie University, Sydney, New South Wales, Australia

${ }^{5}$ Department of Educational Studies, Faculty of Human Sciences, Macquarie University, Sydney, New South Wales, Australia

${ }^{6}$ Sydney Medical School, The University of Sydney, Sydney, New South Wales, Australia

${ }^{7}$ Royal North Shore Hospital, Sydney, New South Wales, Australia

${ }^{8}$ Department of Psychology, Macquarie University, Sydney, New South Wales, Australia

${ }^{9}$ Department of Diabetes and Endocrinology, Blacktown and Mount Druitt Hospital, Sydney, New South Wales, Australia

${ }^{10}$ School of Medicine, Western Sydney University, Sydney, New South Wales, Australia

Contributors RM, CMC and AM were involved in study design. RM wrote the first draft of the protocol, and all authors were involved in critical revision of the protocol. 
Funding Philanthropic donor.

Competing interests None declared.

Patient consent for publication Not required.

Ethics approval Ethical approval was obtained from the NSW Population Health Services Research Ethics Committee (HREA: 018HRE0904).

Provenance and peer review Not commissioned; externally peer reviewed.

Data availability statement No data are available.

Open access This is an open access article distributed in accordance with the Creative Commons Attribution Non Commercial (CC BY-NC 4.0) license, which permits others to distribute, remix, adapt, build upon this work non-commercially, and license their derivative works on different terms, provided the original work is properly cited, appropriate credit is given, any changes made indicated, and the use is non-commercial. See: http://creativecommons.org/licenses/by-nc/4.0/.

\section{REFERENCES}

1. World Health Organization. The global strategy for women's, children's and adolescents' health (2016-2030). Geneva: World Health Organization, 2015.

2. Dahlquist G, Källén B, Swedish Childhood Diabetes Study Group. School performance in children with type 1 diabetes--a populationbased register study. Diabetologia 2007;50:957-64.

3. Jones CM, DeWalt DA, Huang I-C. Impaired patient-reported outcomes predict poor school functioning and daytime sleepiness: the PROMIS pediatric asthma study. Acad Pediatr 2017;17:850-4.

4. Miziara CSMG, de Manreza MLG, Mansur L, et al. Impact of benign childhood epilepsy with centrotemporal spikes (BECTS) on school performance. Seizure 2012;21:87-91.

5. Prasad MR, Swank PR, Ewing-Cobbs L. Long-Term school outcomes of children and adolescents with traumatic brain injury. $J$ Head Trauma Rehabil 2017;32:E24-E32.

6. Wood J. Effect of anxiety reduction on children's school performance and social adjustment. Dev Psychol 2006;42:345-9.

7. Faraone SV, Biederman J, Lehman BK, et al. Intellectual performance and school failure in children with attention deficit hyperactivity disorder and in their siblings. J Abnorm Psychol 1993:102:616-23.

8. Hoffmann I, Diefenbach C, Gräf C, et al. Chronic health conditions and school performance in first graders: a prospective cohort study. PLoS One 2018;13:e0194846.

9. Azzam N, Oei J-L, Adams S, et al. Influence of early childhood burns on school performance: an Australian population study. Arch Dis Child 2018;103:444-51.

10. Maslow GR, Haydon A, McRee A-L, et al. Growing up with a chronic illness: social success, educational/vocational distress. J Adolesc Health 2011;49:206-12.

11. World Health Organization and UNICEF. World report on child injury prevention. Geneva: World Health Organization, 2008.

12. Mitchell RJ, Curtis K, Foster K. A 10-year review of child injury hospitalisations, health outcomes and treatment costs in Australia Injury Prevention 2018;24:344-50.
13. Foster K, Young A, Mitchell R, et al. Experiences and needs of parents of critically injured children during the acute hospital phase: a qualitative investigation. Injury 2017;48:114-20.

14. World Health Organization. The world health report 2002 - reducing risks, promoting healthly life. Geneva: World Health Organization, 2002.

15. Hawley CA. Behaviour and school performance after brain injury. Brain Inj 2004;18:645-59.

16. Crump C, Rivera D, London R, et al. Chronic health conditions and school performance among children and youth. Ann Epidemiol 2013;23:179-84.

17. Australian Institute of Health and Welfare. Australia's health 2018. Canberra: AlHW, 2018

18. Australian Institute of Health and Welfare. A picture of Australia's children 2012. Canberra: AlHW, 2012.

19. ACARA. National assessment program: literacy and Numeracy. Sydney: ACARA, 2017.

20. Mitchell RJ, Curtis K, Braithwaite J. Health outcomes and costs for injured young people hospitalised with and without chronic health conditions. Injury 2017;48:1776-83.

21. Mitchell RJ, Herkes G, Nikpour A, et al. Examining health service utilization, hospital treatment cost, and mortality of individuals with epilepsy and status epilepticus in New South Wales, Australia 2012-2016. Epilepsy \& Behavior 2018;79:9-16.

22. Australian Institute of Health and Welfare. National Hospital morbidity database datacubes. Canberra: AlHW, 2018.

23. NSW Ministry of Health. HealthStats NSW North Sydney: NSW Ministry of health, 2018. Available: http://www.healthstats.nsw.gov. au/ [Accessed 2 Dec 2018].

24. Australian Bureau of Statistics. 1270.0.55.005 - Australian Statistical Geography Standard (ASGS): Volume 5 - Remoteness Structure, July 2011. Canberra: Australian Bureau of Statistics, 2013.

25. Lower T, Mitchell RJ. Farm injury hospitalisations in New South Wales (2010 to 2014). Aust N Z J Public Health 2017;41:388-93.

26. Australian Bureau of Statistics. Census of population and housing: socio-economic indexes for areas (SEIFA), Australia. catalogue NO: 2033.0.55.001. Canberra: Australian Bureau of Statistics, 2011.

27. Osler T, Rutledge R, Deis J, et al. ICISS: an international classification of Disease-9 based injury severity score. Journal of Trauma Injury Infection and Critical Care 1996;41:380-8.

28. Stephenson S, Henley G, Harrison J, et al. Diagnosis-Based injury severity scaling. Adelaide: AlHW, 2003.

29. Dayal S, Wren J, Wright C. Mapping injury severity scores against hospitalisation day stays for injury priority areas (excluding workplace injury). Wellington: Public Health Intelligence, Health and Disability Systems Strategy Directorate, Ministry of Health, 2008.

30. Maslow GR, Haydon AA, Ford CA, et al. Young adult outcomes of children growing up with chronic illness. Arch Pediatr Adolesc Med 2011;165:256-61.

31. Nagan D. Group-based modeling of development. Massachusetts: Harvard University Press, 2005.

32. Australian Institute of Health and Welfare. Australia's hospitals 2014-15 at a glance. Canberra: Australian Institute of Health and Welfare, 2016. 